\title{
〔23〜24〕ビニル誘導體の重合性と化學㩐造との關係（I II）
}

第1報序論

$$
\text { 千一行利三 }
$$

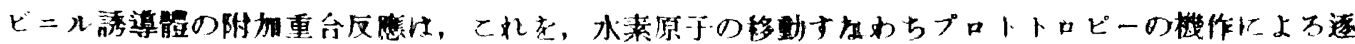

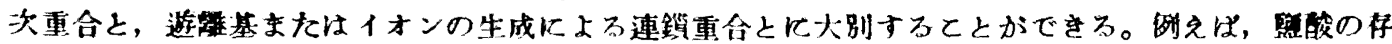

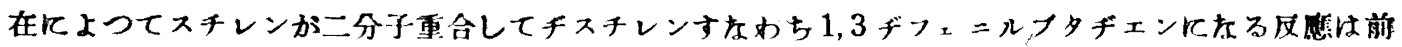

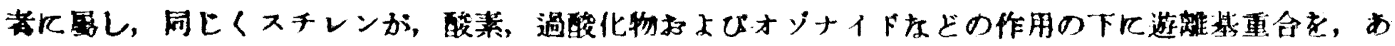

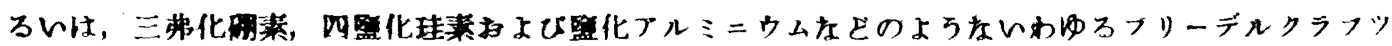

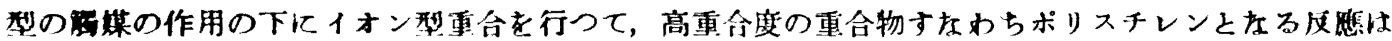

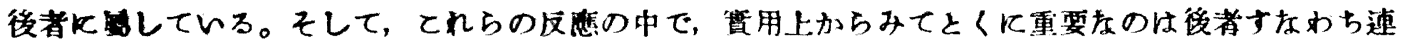
鉬重合であつて，てれによつているいろと重要在高分子化合物の得られているととは，よく知られて

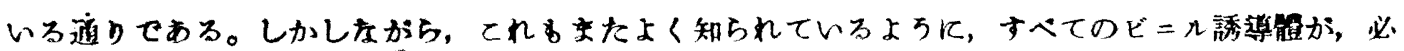

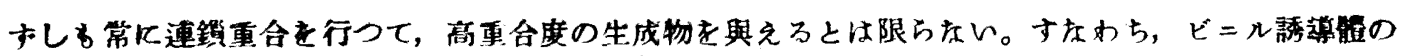

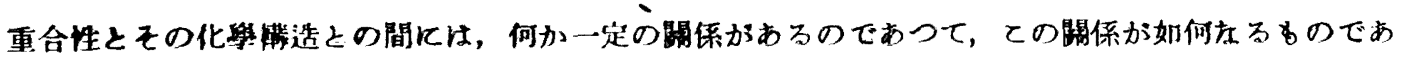

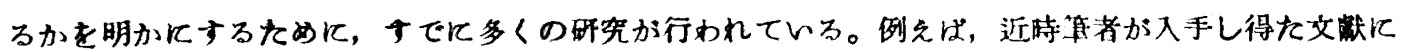

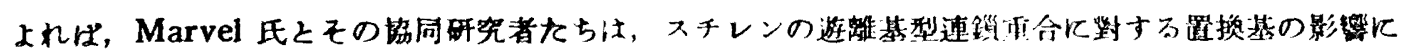
ついて多くの研究を行い，次の結果を得ていス。

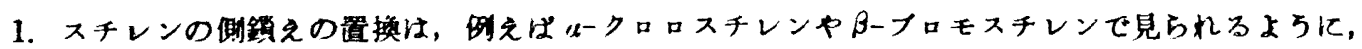

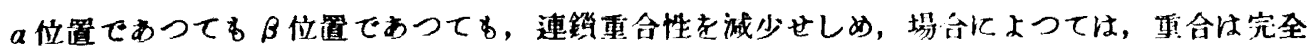
に阻止されてしまう。

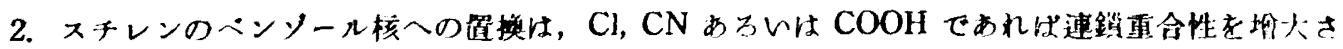
せるが，：トロ基の置换は重合を阻止する。

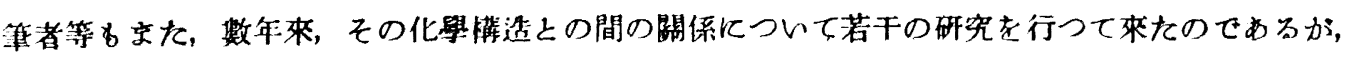
それは次の上5な前提的の假謨あるいは研究假說に基いているるのである。すなわちます $\mathrm{R} \cdot \mathrm{CH}=$

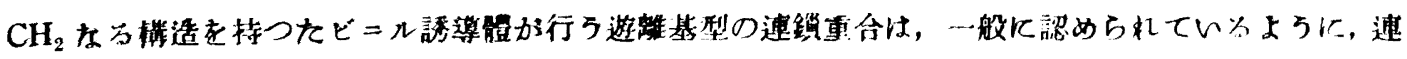
鎖生起，連鍤生長および速鎖終止の三つの過程からなつているとするてとがで方。

連鍤生起 $\mathrm{K}+\mathrm{R} \cdot \mathrm{CH}=\mathrm{CH}_{2} \rightarrow \underset{k}{\mathrm{~K}}-\underset{\mathrm{K}}{\mathrm{C}} \mathrm{H}-\mathrm{CH}_{2}-$

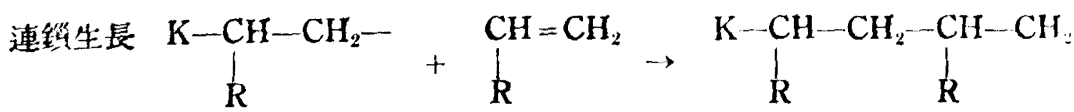




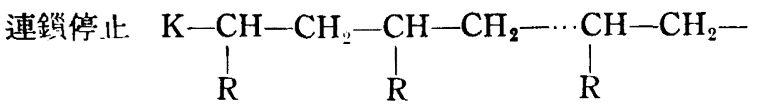

$\rightarrow$ 安定化した連錎重合體

ただし，最初の連贘生起の反隹（1）においてK と記したものは，車合を生起する觸媒の分子またはそ の分解によつて生じた遊蜼基を表わするのであつて，例えば，ての種の觸媒として過酸化ベンジイル $\mathrm{C}_{6} \mathrm{H}_{5} \cdot \mathrm{CO} \cdot \mathrm{O} \cdot \mathrm{O} \cdot \mathrm{CO} \cdot \mathrm{C}_{6} \mathrm{H}_{5}$ 老使つた場命には，乙の分子が二つに趾れることによつて坐した $\mathrm{C}_{6} \mathrm{H}_{5} \cdot \mathrm{CO}$

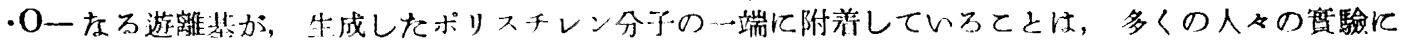

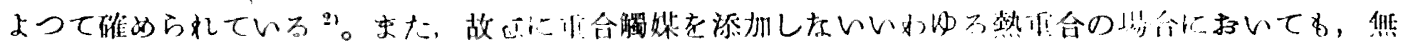

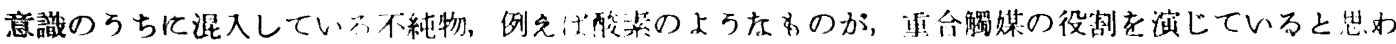

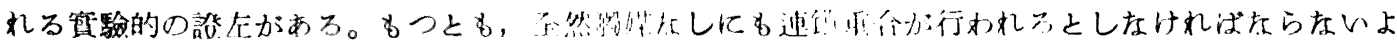

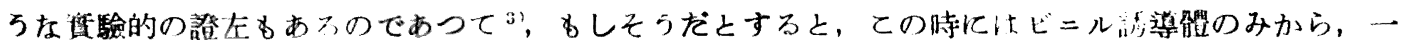

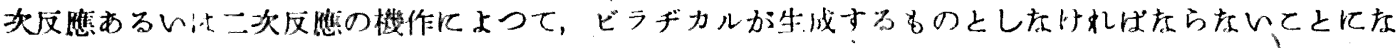

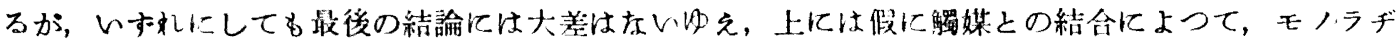
カルが生成するすのとしておいた。

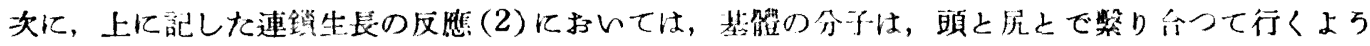

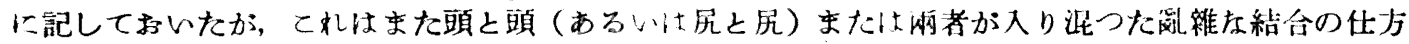

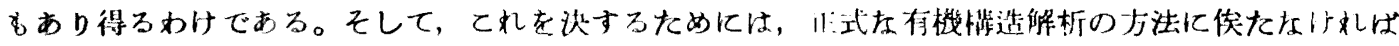

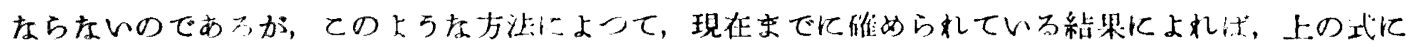

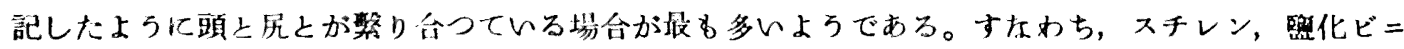

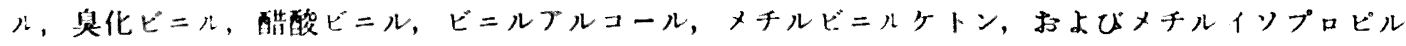

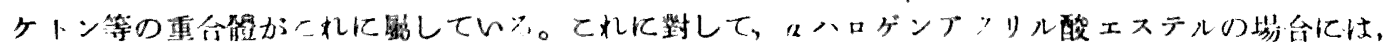

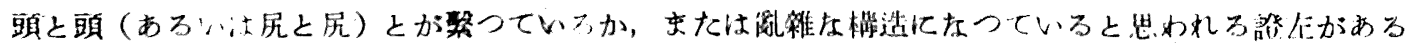

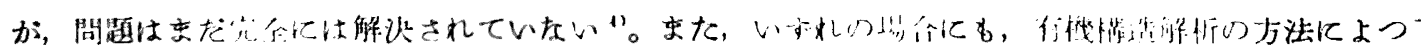

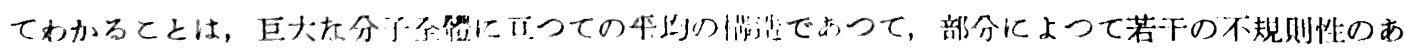

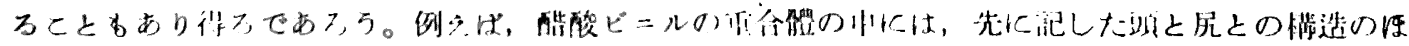

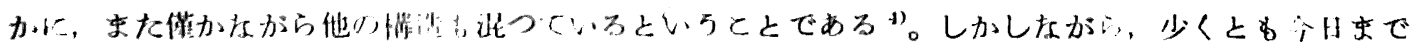

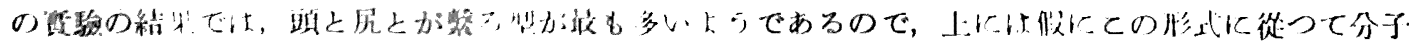

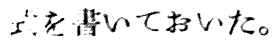

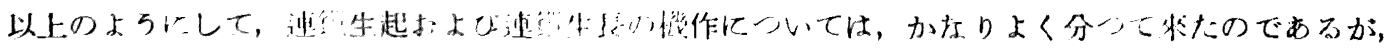

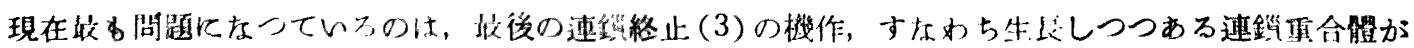

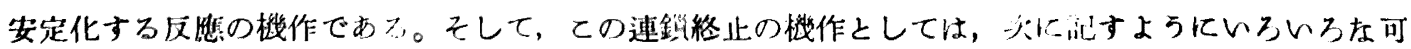
能性がある。

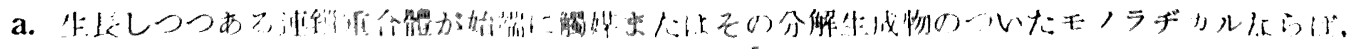

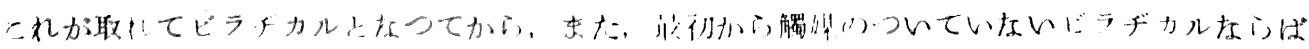

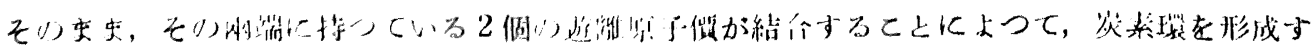


る。

b. 生長しつつある連鋢重合體がモノラヂカルならば, その末端に持つている遊嶣原子洒によつ

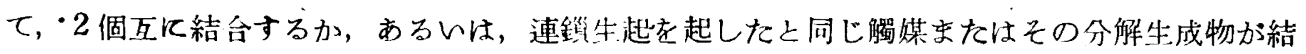
着する。

c. 生長しつつある連鎖重合體の分子內あるいは分子間，また，溶液を用いた增合には，乙れと の間に水素原子の授受が行われて，遊蜼原子價が消隇する。

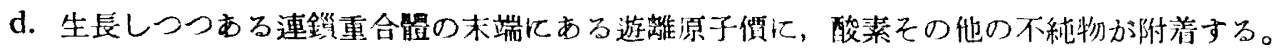

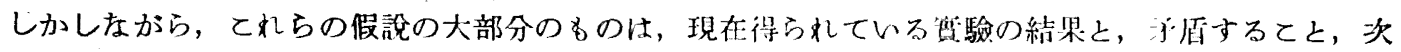
に記す如くである。

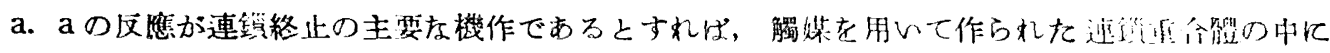
は，觸媒の分子またはその分解生成物は含文れてていない䈏であるが，䖯绦には先に記したよ5 に含まれている。また，連鎪重合䯣は一般に炭素環を持つているような性質を示さない。

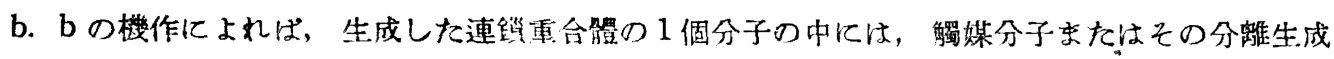
物である遊離基か２個含まれている筈である。しかしながら，少くともスチレンを邀酸化べン ソイルを用いて重合させた埃合には，生成したポリスチレンの1個分子について， $\mathrm{C}_{6} \mathrm{H}_{5} \cdot \mathrm{CO}$. O一なる遊離基は，平均して 1 個しか含东れていない。

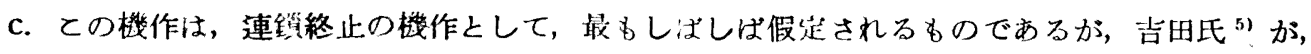
スチレンを重フルコールおよび重ベンゼンの溶液の中で重合させた蜞驗の結果によれば, 生成

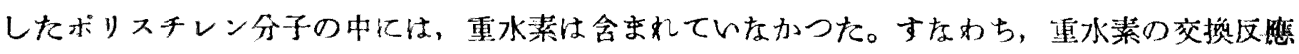
は起つてい枯いのであつて，このてとは，少くとも，スチレンをフルコールおよびベンゼンの

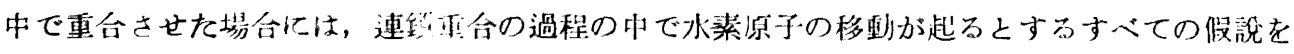
“拒夻する。

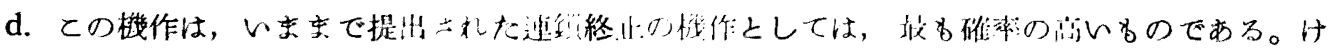

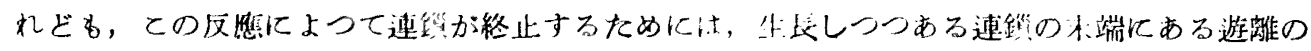

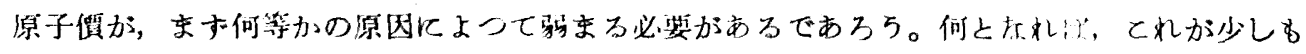

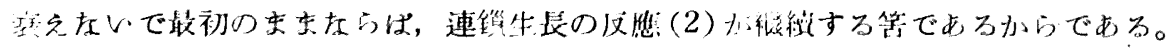

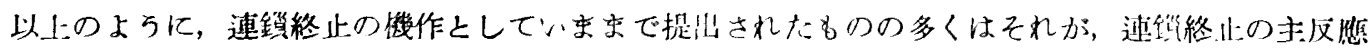

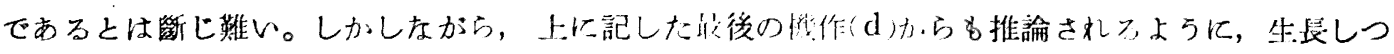

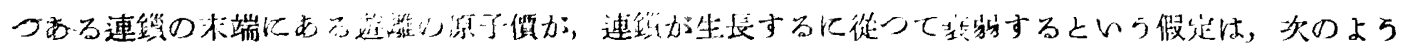
な推論から，最る確からしく思われるのである。

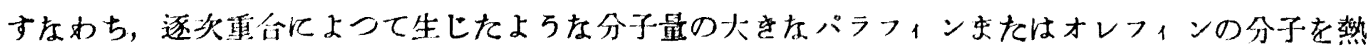

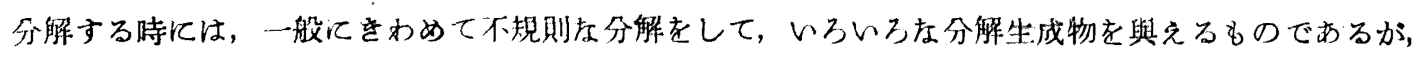

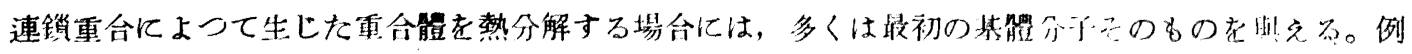
えば，ボリスチレンを加熱すれば，容易に分解してスチとンを生しる。このととは，連錎車合骿の内 
部においては，基體分子間の結合は，基體分子內の絬公上りわ物い上いらととを示するのであり，從

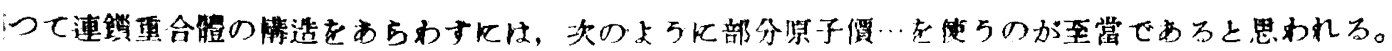<smiles>[R]C([X])CCC([R])CC([R])[R]</smiles>

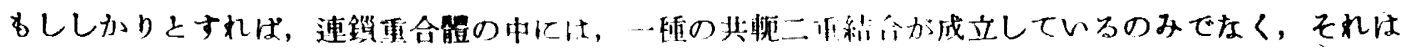

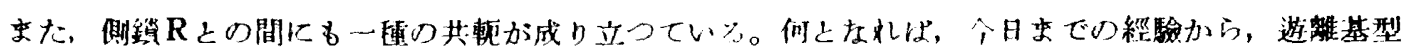

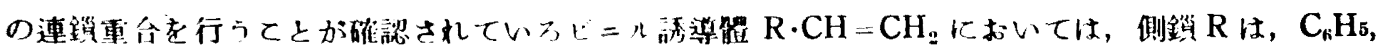

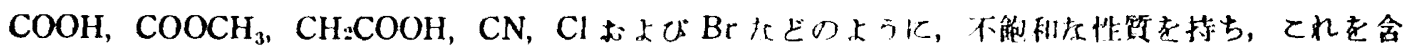

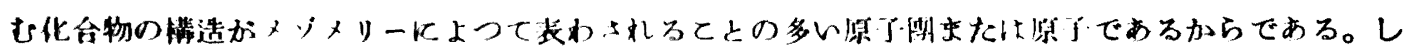

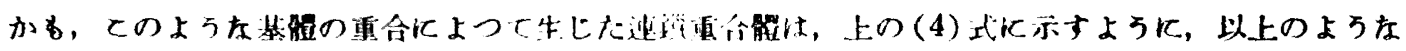

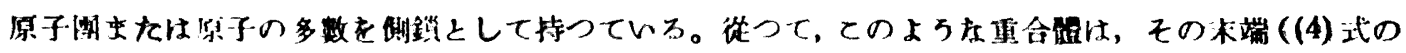

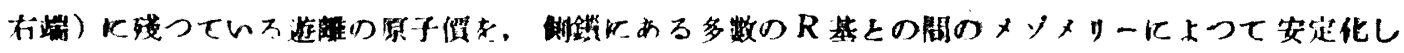
ていろととが推稌されろ。

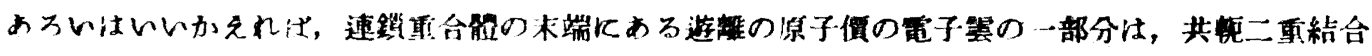

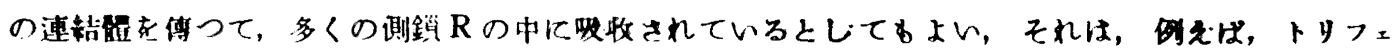

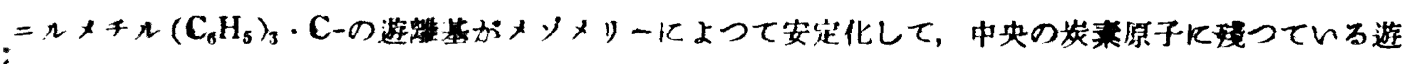

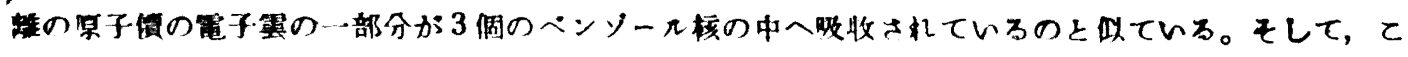

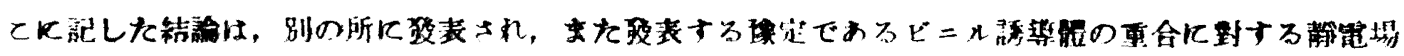

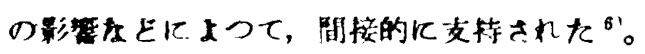

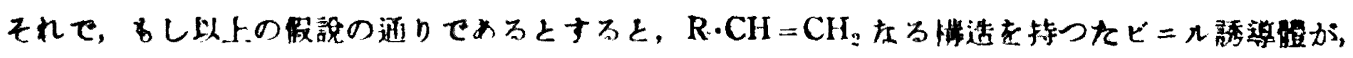

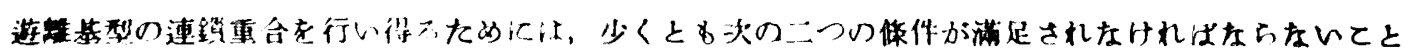
に片る

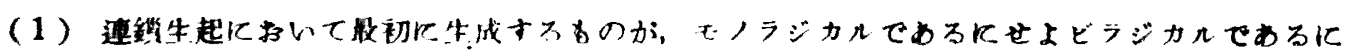

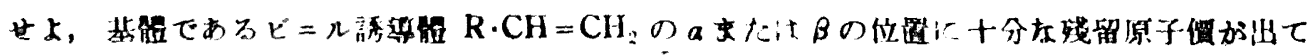
以そとと。

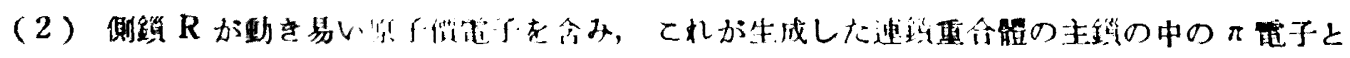

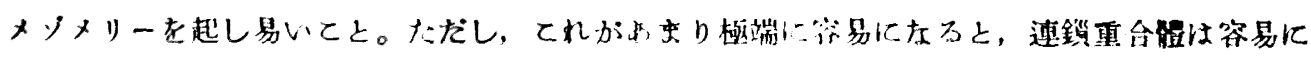

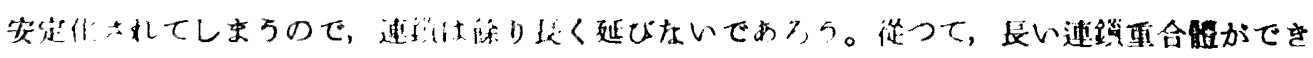

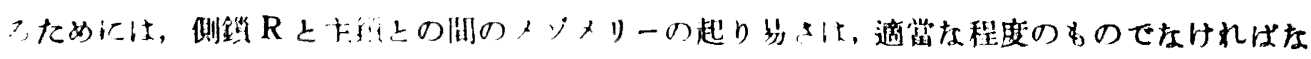
in

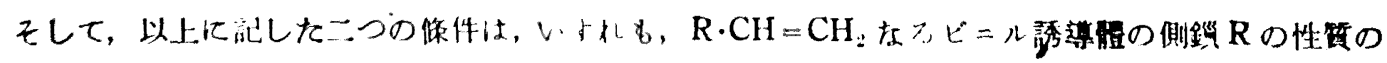

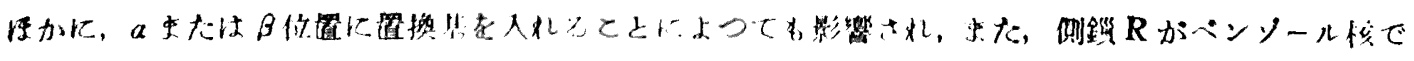

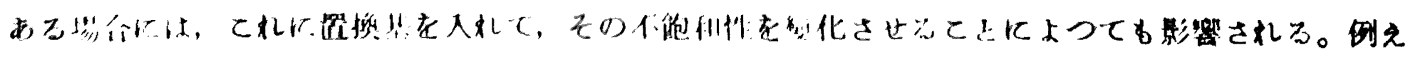

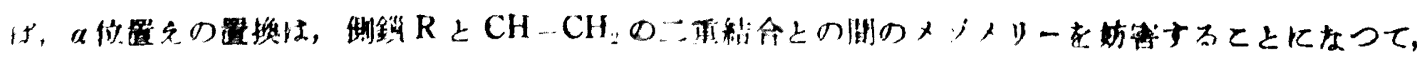




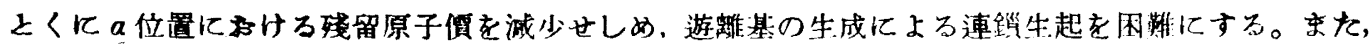

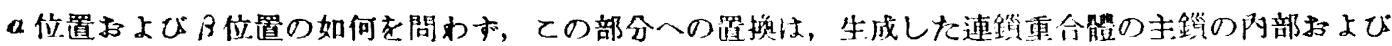

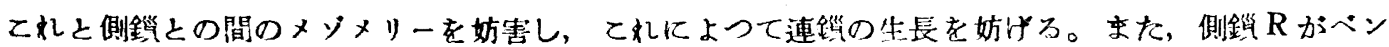
ゾール核である時に，てれにニト口基のようなるのを入れて，その不能和性をあまりに坦大させる封 は，主鎖と側錎との間のメジメリーが過度となつて，連錟はかえつてあまり延びないであろろ。そし て，てれらの結諭のあるものは，先に記した Marvel 氏等の貫驗結果も示しているが，筆者等は上記 の前提的假說または研究假馀に從つて，逐次に研究を進めて行つたのであつて，その結果については， 次報以下に順次に報告する。

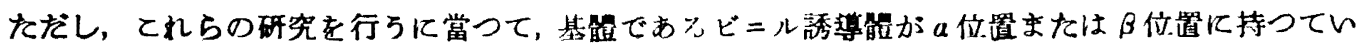

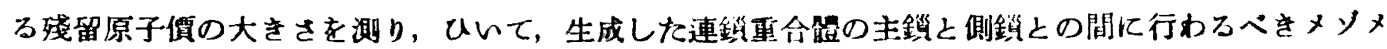
リーの强さを推測するには，基得分子の分子屈折の過超 (Exaltation)を使つてみた。すないち、多 くの有機化合物の分子屈折は，その成分元素の原子屈折から架筷に上つて求められるものであるが，

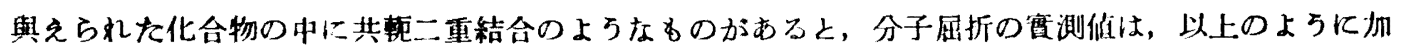

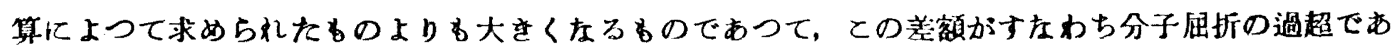

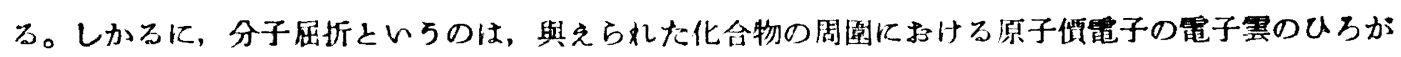
りを表わしているるのであるから，このような過超が起るということは，與えられた分子の周潘にい

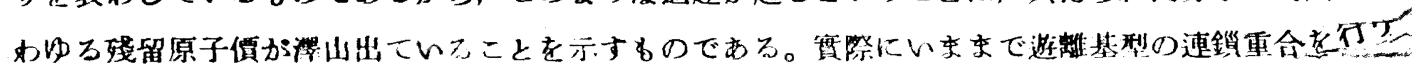
ことが知られているるのは，例えばスチレン $\mathrm{C}_{6} \mathrm{H}_{5} \cdot \mathrm{CH}=\mathrm{CH}_{2}$ 枯どのように，大きな分子屈折を示し てレる。

スチレンの分子 用折 (D 線)

\begin{tabular}{|c|c|c|}
\hline 36.81 & $\begin{array}{c}\text { 就 算倠 } \\
35.07\end{array}$ & $\begin{array}{c}\text { 渦 敖 } \\
1.74\end{array}$ \\
\hline
\end{tabular}

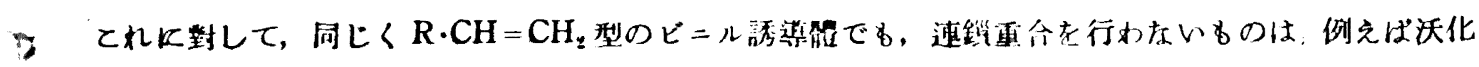
ビニル J.CH $=\mathrm{CH}_{2}$ 友どのように, 分子届折の過超を示さない。

\begin{tabular}{|c|c|c|}
\hline \multicolumn{3}{|c|}{ 民化ピニルの分子同折（D線） } \\
\hline$a^{2}$ & 計項值 & 過 超 \\
\hline${ }_{0}$ & 23.77 & -0.12 \\
\hline
\end{tabular}

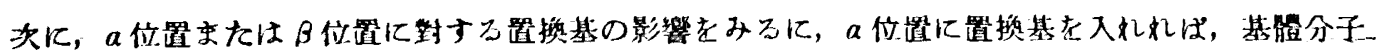
の $\mathrm{R}$ 基と一 $\mathrm{CH}=\mathrm{CH}_{2}$ との間のメソメリ一が妨㕩される結果として，a位置における牫留原子㵋が減

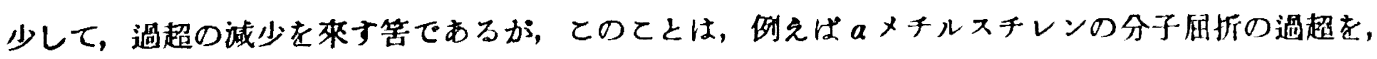
先に記したスチレンのるのと比べれ㴖かかるように，一般的の事萁である。

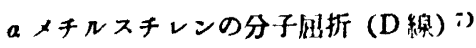

\begin{tabular}{|c|c|}
\hline 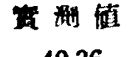 & 計算估 \\
\hline
\end{tabular}

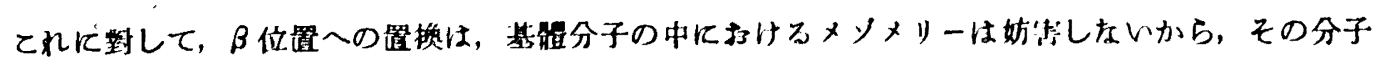

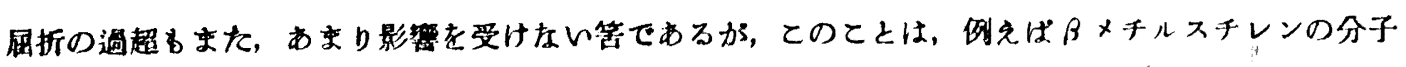




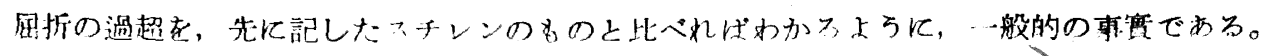

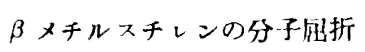

$\begin{array}{ccc}\text { 管 测 值 } & \text { 計算 } & \text { 值 } \\ 41.13 & 39.69 & 1.44\end{array}$

てのよ5に，可能な壦会には，分子届折の過超によつて，基體分子の不飽和度を測りながら；その 重合性を賽驗して行くのが本研究の目的である。

\section{文 到}

1) C. E. H. Bawn; "The Chemistry of High Polymer", London, 1948, p 15

2) 吉田統一; 日化, 68 (1947) 45

B. E. Tate: J. Am. Chem. Soc., 65 (1943), 517, P. D. Bartlett, J. Cohen; ibid., 65 (1943), 543, A.

T. Blomçuist, J. R. Johnson, H. J. Syke; ; ibid., 65 (1943), 2446, H. F. Pfann, F. J. Salley, H. Mark; ibid, 66 (1944) 984, C. C. Price, R. W. Kell, E. Krebs; ibid., 68 (1946), 1686

3) 竹村宫久雄; 末發数

4) C. E. H. Bawn;交噳 1.) p. 13

5) 告田統一; 月化, 61 (1940), 839, 844, 68 (1947) 31,45

6) T. Titani, G. Mesituka; Scientific Papers from Osaka University, No 4 (1949)

7) 中塚和夫；本報第 2 㢳

第 2 報 $а$ メチルスチレノとßーメチルスチレンの車合性

中塚和夫

\section{1. 緒言}

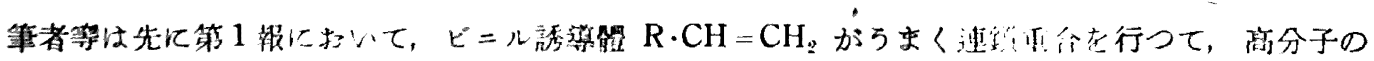

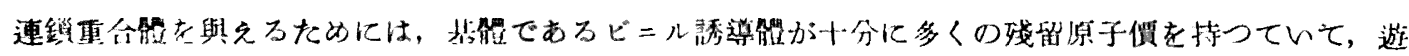

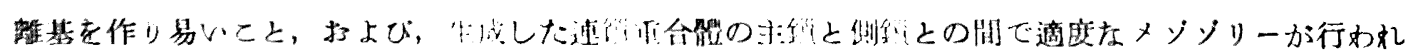

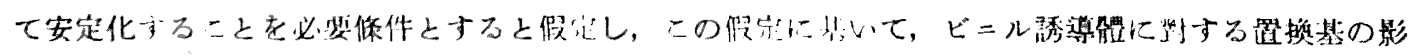

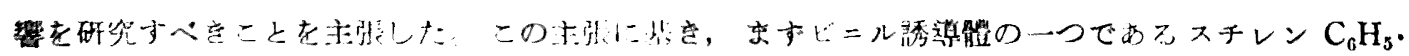

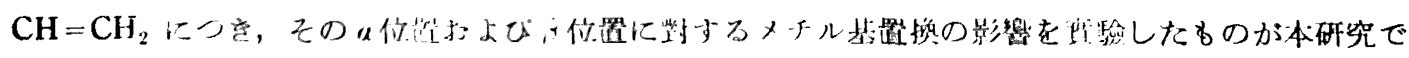

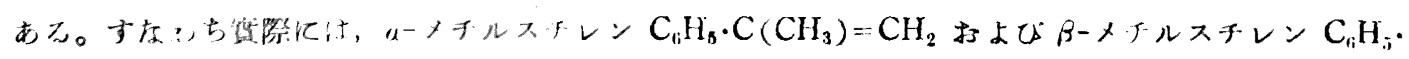

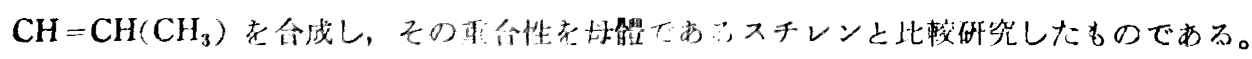

\section{2. 試料の合成}

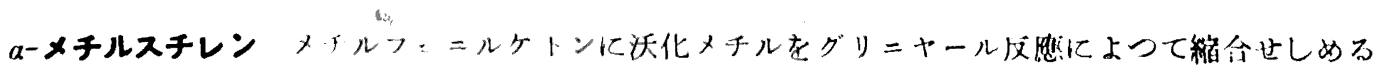

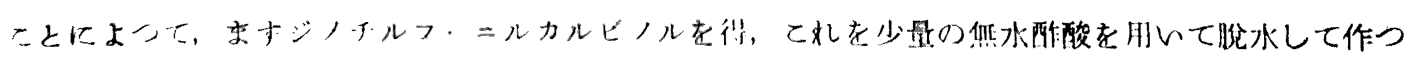

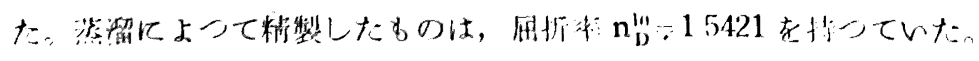

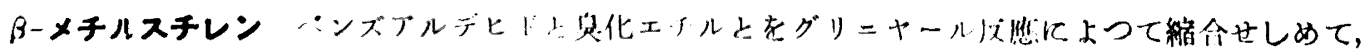

